\title{
The Lived Experiences of Undergraduate Nursing Students Learning Drug Dosage Calculation \\ Marie-Bernard Lazare
}

3002 SW Buena Vista Drive, Palm City, Florida 34990, USA

\section{Abstract}

Background: Competence in dosage calculation represents a challenge that seems to be almost insurmountable for nurses as well as nursing students. The lived experiences of nursing students in the context of learning medication dosage calculation have not been explored for description and interpretation.

Aim of The Study: The purpose of this study was to gain more insight about undergraduate nursing students' lived experiences in learning medication dosage calculation.

Methods: A purposive sample was selected to investigate the following question: What are they lived experiences of undergraduate nursing students studying medication dosage calculation? Data were collected through face-to-face semi-structured interviews, which the researcher transcribed verbatim, and the participants reviewed for validation. The combined interpretive and descriptive method of van Manen guided the characteristics of the thematic data analysis conducted to determine the findings.

Results: The related themes of signifying, repeating, analyzing, verifying, maintaining consistency are tied to the overarching theme of assuring safety, which emerged as the essence of the participants' lived world of learning drug dosage calculation.

Conclusions: This study contributed, to some extent, to filling the empirical gap identified in the literature review. These participants gave rich, in-depth accounts of how they embodied drug dosage calculation to attain competence that they need to administer correct dosage of medications to their patients.

\section{Introduction}

Competency in drug dosage calculation is crucial for safe medication administration, but it continues to be a challenge among nursing students, which is a deficiency that reflects in their ability to safely perform medication dosage calculation as students, and as well as when they become nurses in the clinical settings. The Institute of Medicine reported that there are many factors that can contribute to medication errors in the health care settings [1]. Medication administration is one of the factors that is directly associated to nursing care. Nurses are responsible and accountable for making sure accurate medication doses are administered to patients [2] Nurse competency, which starts in academia, is one of the essential characteristics of the nursing profession that must be accomplished with no doubt to assure safe patient care, especially in medication dosage calculation skills [2]. To minimize factors that can jeopardize patient safety, health care leaders have adopted various measures to assure safe medication administration, but they have not yet found a method that is without challenges [3]. Nursing education has been diligent in trying different teaching approaches that can help students develop proficiency in drug dosage calculation, but the issues continue to be very challenging. Because the problem continues to persist, the efforts by nursing education and the health care industry need new insights to facilitate better outcomes. This study, to investigate the lived experiences of undergraduate nursing students who have taken a drug dosage calculation course, provided data that could lead to a better understanding of this phenomenon from the student's perspective.

\section{Background}

Medication dosage calculation by nurses has been recorded as one of the common risks to patient safety [4]. It has been reported that as many as 7,000 individuals die each year due to medication errors [5]. Inaccurate doses can result in patient morbidity and mortality [6]. These outcomes can be detrimental to patients, providers, as well as the health care industry [7]. Although many factors can negatively impact medication administration, accurate dosage calculation is one of the important skills a nurse must have to assure delivery of quality safe nursing care to their patients. Aptitude in dosage calculation is one of the critical aspects of nurse competency that has serious impacts on safe medication administration, which is an ongoing problem in health care that is of great importance because it concerns patient safety [8]. A cross-sectional study for evaluation of calculation skills showed that $92 \%$ of student nurses and $89 \%$ of nurses failed the drug calculation test [4]. The diversified and complex health care needs expect new nurses to enter the workforce with mastery in dosage calculation skills [9]. An integrative review, conducted to examine the state of the literature on effective strategies for teaching undergraduate student nurses drug dosage calculations, revealed that four types of strategies, such as traditional pedagogy, technology, psychomotor skills, and blended learning, were beneficial to student learning outcomes [10]. It is evident through research that there is an urgent need for improvement in safe drug dosage calculation competence [2].

Competency in dosage calculation skills remains the obligation of nursing education. Making sure nursing students are proficient in dosage calculation skills is a crucial contribution to safe patient care [11]. There are empirical evidences of different views on the best teaching strategies to help students achieve mastery in dosage calculation skills [12]. It is a continuous trial and error in academia to rearrange curricula to find the correct teaching methods and strategies "Corresponding Author: Dr. Marie-Bernard Lazare, PhD, MSEd, MSNEd, RN 3002 SW Buena Vista Drive, Palm City, Florida 34990, Tel: (772) 631-5605; E-mail lazarejolie@msn.com

Citation: Lazare MB (2018) The Lived Experiences of Undergraduate Nursing Students Learning Drug Dosage Calculation. Int J Nurs Clin Pract 5: 297. doi https://doi.org/10.15344/2394-4978/2018/297

Copyright: (c) 2018 Lazare. This is an open-access article distributed under the terms of the Creative Commons Attribution License, which permits unrestricted use, distribution, and reproduction in any medium, provided the original author and source are credited. 
to help students develop proficiency in drug dosage calculation. However, the teaching methods emphasize the mathematical or operational aspects of dosage calculation rather than the conceptual aspect of it. For the most part, student anxiety, fear, and self-efficacy about mathematics have been the focus of the empirical literature [13]. Curriculum and continuing education development should focus on both the mathematical and conceptual aspects of dosage calculation [14]. The existing empirical literature has been a very important aspect in addressing the issues involved in dosage calculation competency. However, investigating students' perspectives on issues that concern proficiency in drug dosage calculation may open the way for a paradigm shift in the approaches nursing education has used so far to educate students on drug dosage calculation. In a quantitative study, a semi-structured questionnaire was utilized to investigate the impact that 67 nursing students' learning styles and perceptions have on their drug dosage calculation mastery skills [13]. In conclusion, the study underlined that knowing how students perceive the strategies being taught to them could guide curriculum development to focus on what is necessary for mastery of drug dosage calculation from the students' perspectives [13]. The following section will address the computation methods for dosage calculation.

Drug dosage calculation is usually performed using either one of three computation methods such as dimensional analysis, traditional formula method, and ratio and proportion. Dimensional analysis is a method that works with units to solve problem by using a known equivalent [15]. For example, convert 220 pounds (lb) in kilogram ( $\mathrm{kg}$ ) using the known equivalent $2.2 \mathrm{lb}=1 \mathrm{~kg}$. The traditional formula method uses the formula $\frac{\mathrm{D}}{\mathrm{H}} \times \mathrm{Q}=\mathrm{x}$ to solve dosage calculation problems within the same system [15]. In this formula, D is the dosage ordered, $\mathrm{H}$ is the dosage available on hand, $\mathrm{Q}$ stands for the quantity of dosage available, and $\mathrm{x}$ is the dosage being calculated or the unknown. For example, the order is for 60 milligrams $(\mathrm{mg})$, and what you have on hand from the pharmacy is $20 \mathrm{mg}$ per 5 milliliters $(\mathrm{mL})$. In this case, $\mathrm{D}$ is $60 \mathrm{mg}, \mathrm{Q}$ is $5 \mathrm{~mL}$, and $\mathrm{H}$ is $20 \mathrm{mg}$ or $\frac{60 \mathrm{mg}}{20 \mathrm{mg}} \times 5 \mathrm{~mL}$. Another method often used to compute drug dosage calculation is ratio and proportion, which includes a numerator and a denominator in relation to one another [15]. To formulate the ratio and proportion in calculating drug dosages, the numerator is the medication that is on hand, and the denominator is the order that needs to be calculated [15]. Because of proven increased in student performance on drug dosage calculation skills when dimensional analysis was used as a teaching method, studies on dimensional analysis have indicated that it is the method more likely to help nursing students improve their dosage calculation skills. Regardless of the method used to calculate drug dosage, the following figure (Figure 1) represents the content information that requires critical thinking skills for successful computation.

\section{Objective}

The purpose of this qualitative phenomenological study was to gain more insight about undergraduate nursing students' lived experiences in learning medication dosage calculation during their undergraduate nursing studies. No study of this nature was found in current literature. This study gave nursing students the opportunity to voice their experiences in learning medication dosage calculation. This study sought to understand the essence of the lived experiences of undergraduate nursing students mastering drug dosage calculation.

\section{Research Question}

This phenomenological inquiry was guided by the following research question: What are the lived experiences of undergraduate nursing students learning medication dosage calculation?

\section{Methods}

The purpose of this qualitative phenomenological study was to gain more insight about undergraduate nursing students' lived experiences in learning medication dosage calculation. This study sought to

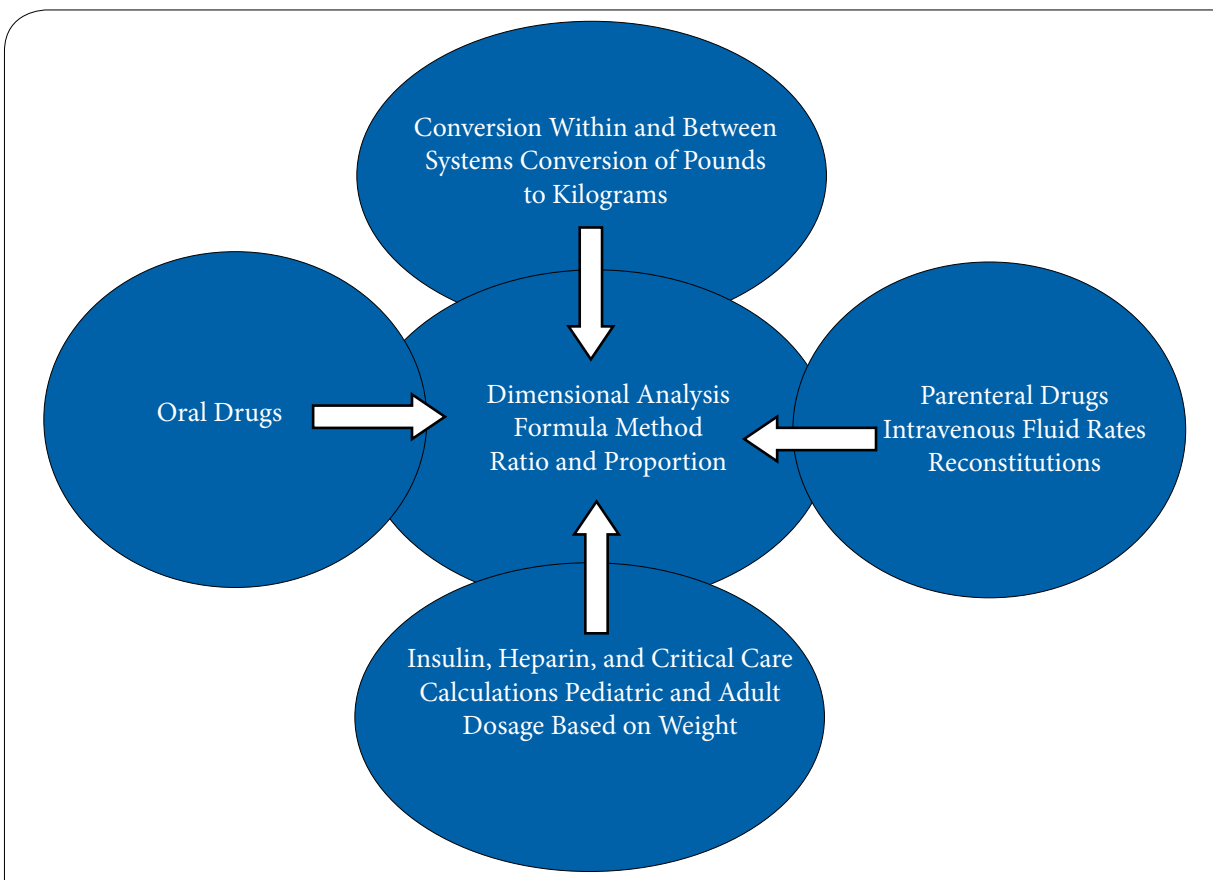

Figure 1: Types of content for drug dosage calculation regardless of methods being used (Lazare, 2016). 
give these students a voice to articulate their personal experiences while learning medication dosage calculation. This study sought to understand the essence of the lived experience of undergraduate nursing student with dosage calculation. This method is based on the philosophical viewpoint of Heidegger whose focus was on how human beings construct meanings as they experience life, as opposed to Husserl's philosophical viewpoint which emphasized on describing the human experience as perceived in the consciousness [16]. For this study, the van Manen's approach was followed. Van Manen followed Heidegger's method of phenomenology and used hermeneutics so that the researcher could obtain deep, descriptive data, and give meaning to the experience [17]. This approach is accomplished by overlapping description, interpretation, and language activities to describe what it means for participants to be "in-the-world" [17].

\section{Study Design}

The research methodology appropriate for this study is hermeneutic phenomenology developed by Max van Manen. This qualitative inquiry interpreted the lived world of undergraduate nursing students while they are learning medication dosage calculation. Learning medication dosage calculation is a complex human phenomenon. It is complex because of its conceptual and operational components that require critical thinking ability. This phenomenological inquiry sought to determine how these nursing students perceived and interpreted learning dosage calculation skills. Phenomenology aims at discovering the essential commonality in the lived experiences of individuals [18]. The participants' meanings of their experiences with the phenomenon were accessed using descriptive and interpretive verbatim. Phenomenology bridges the gap between what really exists (metaphysics) and epistemology or the manner in which knowledge is gained [18]. Qualitative research investigates the understanding people have of phenomena in their lives [18].

\section{Sample and Setting}

A purposive method of selecting the sample was adopted for this research study. This sampling method was congruent with the paradigm of this study, which is interpretive. Purposive sampling facilitates the selection of participants that better represent the phenomenon of interest [18]. It is of utmost importance for the participant's lived experience to elicit deep understanding of the phenomenon being studied [17]. Therefore, the selection of nursing students, attending a dosage calculation course in an undergraduate baccalaureate nursing program in South Florida, was appropriate for this study. Upon receiving Institutional Review Board (IRB) approval at Barry University, three schools in the South Florida area were contacted for permission to access their nursing students through the posting of flyers. These flyers were to recruit nursing students and were posted in different areas to elicit awareness for voluntary participation in the study. This method of sampling allowed the researcher to ensure the inclusion of people with diverse backgrounds and experiences with the phenomenon. Data saturation, which is a process of collecting information from interviewing participants until no new themes are observed, is an important aspect in establishing sampling size [19]. However, there is a lack of consensus as to a specific guideline to determine when saturation occurs [19]. Instead of formulating any specific determination of sample sizes for phenomenological research, a wide range of sample sizes, such as 1 to 325 participants, has been seen in use in qualitative research [18]. As such, for this study a maximum of 30 participants was sought. However, upon reaching data saturation 11 students became the participants from whom data were collected.

\section{Data Collection}

Data collection was done through face-to-face interviews of individuals. The researcher conducted interviews of the participants using a non-directive style with open-ended, questions which allowed them to freely describe their thoughts or opinions. When needed for clarification of participants' information, the researcher used open-ended style of questioning. The duration of the first interview would last no more than 60 minutes, and the second interview would last 30 minutes. The longest interview lasted the entire 60 minutes, and the shortest one lasted 20 minutes. All narrative data obtained during the interview were recorded and transcribed by the researcher. Upon completion of the transcription of the first interview, a second interview was scheduled to review and confirm the transcribed data obtained from the first interview. The interviews were arranged so that the selected date, location, and time were mutually convenient for participants as well as the investigator.

The characteristic of this qualitative inquiry was to explore the participants' experiences while learning medication dosage calculation. The interview questions were built in a way to allow the researcher to interpret the lived experiences of the participants in the phenomenon being studied. Therefore, for these questions to achieve this goal, they must be semi-structured and unstructured in nature. Open-ended questions are to facilitate the participants to give rich, and detailed account of their thoughts and opinions on the phenomenon being investigated [20].

\section{Data Analysis}

Qualitative data analysis requires a systematic approach of organizing and reviewing the data to better gain insight on the participants' experiences, and to answer the research question [18]. The researcher entered the world of the participants through their rich, in-depth stories captured during the interviews that were transcribed word for word for accuracy. These transcripts were double-checked, and all adages were included to reflect the vividness, thickness, and richness of the participant's conversations. The researcher was immersed in the process of transcribing the data through writing, rewriting, reading, and rereading. The data were organized and managed in QSR NVivo 10 , a computer software for qualitative research.

The researcher conducted in depth data analysis by applying the hermeneutic circle that consists of reading, reflecting, and thoroughly interpreting the meaning of the participants' lifeworld of drug dosage calculation. These data were analyzed in their entirety for the emergence of themes that explicated the meaning attached to the lived experiences of these nursing students. The narrative data obtained from the students were looked at first to determine the overall essential meaning being conveyed. Any part of the text, which has a theme representing the lifeworlds of the students in learning dosage calculation during their undergraduate nursing studies, was highlighted. Sentences were set apart line-by-line to determine what they might be revealing about the nature of their lived experiences in learning drug dosage calculation.

The combined interpretive and descriptive method of van Manen supports the characteristics of the data analysis that was done for this study to determine the findings, an approach which is referred to "hermeneutic phenomenological reflection" [17]. 


\section{Ethical Considerations}

The project was sent to the Institutional Review Board (IRB) of Barry University for approval before recruitment and data collection begin. The participants' information is kept confidential. The demographic data sheet included the pseudonym selected by each participant. The interview data and the participants' signed consents are kept in separate locked cabinets in the researcher's private study at home. Data are stored in a safe area that only the researcher can access, and they will be destroyed after 5 years. Before the participants sign the consents, all information pertinent to the study was disclosed to them. The researcher explained the nature of the study and what was expected from the participants, and what to expect from the researcher. The participants were informed that there was no risk involved in this study, and that they reserve the right to drop out of the study at any given time.

\section{Rigor}

The term rigor brings attention to the quality or trustworthiness of the research process [21]. Researchers can employ several techniques to assure the trustworthiness of qualitative inquiries. Certain criteria, such as credibility, dependability, confirmability, and transferability, have been established to ensure scientific rigor in qualitative research [21]. The researcher followed these strategies in this study to establish evidence of trustworthiness for the stakeholders. It is supported that member checking may be simple and cost effective, but it is an appropriate procedure for promoting credibility in a qualitative study [18]. For member checking in this study, the researcher had the participants review their transcribed interviews for clarification and confirmation.

Dependability is assured for interested readers of this study in an audit trail available in the forms of detailed writing of sample selection, data collection, data analysis, data interpretation, reflective journaling, and analytic memos. The confirmability of the interpretation of the lived experiences of the nursing students learning dosage calculation was established by keeping a reflective journal to document personal experiences, thoughts, feelings, and opinions. Therefore, confirmability was established by the researcher making sure that the data interpreted reflect the deep meanings of the participants' lifeworlds. The integrity of the findings of a study is found in the originality of the data collected [22]. In the context of transferability, the use of purposive sampling, thick and rich description of the findings in this study would facilitate stakeholders to formulate association with their own experiences.

\section{Findings}

The participants gave rich accounts of how they have experienced learning drug dosage calculation in their baccalaureate nursing program. By sharing in-depth descriptions of their lived experiences, the participants facilitate the researcher to understand and make meaning of the phenomenon being investigated. The student nurses interviewed were quite enthusiastic about letting the researcher in their lived world of learning drug dosage calculation by participating in faceto-face interviews that were audio taped. One by one they gave rich, vivid, in-depth accounts of their experiences with the phenomenon. The emergent themes of signifying, repeating, analyzing, maintaining consistency, and verifying were linked to the overarching theme of assuring safety. The lived experiences of the participants are reflected in all the themes discovered, but the overarching theme is recurrent across the narratives of all the participants.

\section{Theme One: Signifying}

Nursing students stressed the importance of proficiency in drug dosage calculation skills. They voiced that it is one of the most crucial aspects of the drug administration process.

\section{John Deere said:}

Hum, I found that the drug calculation was important, like make sure you do the math right. Make sure you know what goes where. If I did the math wrong, I'll be like no biggish... and then, when I sort of have an understanding of the actual mechanisms of the drugs, and how they really work in the body, I began to realize that, hum, it's very important that I get this right, and that there is that adage where it's like measure twice got once. So, learning drug dosage calculation is the beginning of this learning how to critically think about how to treat a patient, especially with the different interventions that we can do. So, that's for me what's important about learning drug dosage calculation.

\section{Daphnee stated:}

Accurate dosing is important because if it's not therapeutic, then the patient is not getting the right treatment. And they would have to keep coming back or keep getting readmitted because the dosing was not therapeutic. Hum, we did calculations for pediatrics, and that's very important because pediatric patients are smaller, and any little small, hum, mistake can, have, like, a big effect on them. So, all patients are important, and whatever we do can have an effect. It could be good or bad. So, us as nurses, it's very important to do what we have to do especially with dosage calculation.

\section{Jessica stated:}

So, like, it's very important because, you know, if the doctor orders something, and you know... you have the order, but you have what's available, then you have to, huh, make sure that whatever you calculate, for example, in pediatrics, you have to make sure the dosage is exact. It's very important. Things are not just given to you. You have to make sure it's right. You have to know your six rights of medication. That's what we learned in the courses. With that, you have to make sure that everything is correct.

Layla said:

Drug dosage calculation is important to know to prevent med error, to understand the logic behind it, and how to administer meds because the order may be different than what you have on hand. It means as a nurse I can administer meds with confidence, so that I could reduce errors, and not be worried that I am giving the patient a wrong med.

\section{Meghan Brown explained:}

I think it's important. I think medication understanding what we're giving, and how much we're giving is really important, especially being a nurse. You can make an easy mistake that can affect a patient's life. So, medication is something that needs to be taken very seriously. So, I'm glad we have the opportunity to do it. I know it's very important as a nurse to know. That's why I do my best to learn it to avoid making mistakes. 


\section{Maxie noted:}

Taking a test is an important experience to see if we know the dosage calculation. It's good to test us to know, but it gives a little anxiety each time. But, it's important to not give wrong med to the patient. It means, huh, you need to study so you can be good at it. It's also makes me feel confident to care for patients.

\section{John Doe indicated:}

Hum, it's an important aspect because, uh, even though we have a lot of calculators and computers, it's always good to know, especially in cases of emergencies. If computers are down and you have a calculator you can use your own knowledge to actually solve the problem and take care of our patients safely.

\section{Theme Two: Maintaining Consistency}

Consistency is another thematic aspect of the experiences of the nursing students learning drug dosage calculation. Many of the participants expressed that consistency in any problem-solving method used for drug dosage calculation has remarkably helped them achieve content mastery.

\section{Zeus said:}

You have to learn how to do it, and make sure when you're doing the math, you use those strategies that you've learned in order for me to prevent me from making, you know, mistakes that could cost someone's life. When I'm doing drug dosage calculation, I use dimensional analysis because to me it's more precise. There are different strategies that they've used. Some people use ratio and proportion, but I personally like dimensional analysis because it gives me a more of a clearer path so that I don't miss a step.

\section{Barbarita asserted:}

I learned math in Columbia, my original country. So, for me it was a little challenging because in the United States the way they teach math it was a little different. So, I tried to keep it my way to make it easier for me. I actually use ratio and proportion. For me personally, it's the easiest one, and it's the closest one to what I learned in my original country. Now, when I sit on a math test, which we have to take every single semester, hum, I just feel comfortable, and sure about what I'm doing.

\section{John Doe said:}

I used the formula desired over have. It requires common sense. So, they'll be like say, hum, administer $10 \mathrm{mg}$, and we have two $5 \mathrm{mg}$ capsules, so we give 2 capsules. There is some common sense, and just follow the formula learned in class. The formula is just simple dividing, adding, and subtracting.

\section{Layla stated:}

We use what was ordered over what you have on hand as method, and I understood everything. It's been a very good experience. I am pretty confident about it.

\section{Blue Orchids explained:}

I use desired over have, also known as ordered over available. So, ordered is what the doctor desired and available is what we have. It was kind of tough, but we got through it.

\section{Aset indicated:}

I had a good experience. I had a good instructor. She taught very clearly. She taught, huh, a good way to calculate using dimensional analysis, and I used that for everything.

\section{Daphnee said:}

It was basically a straight forward, learning process. Huh, our professor made it clear on how to do the dimensional analysis. Nothing too hard or difficult with the word problem, yeah, it was pretty easy to understand them.

\section{Theme Three: Verifying}

The participants emphasized that checking and double-checking answers is crucial to identify and correct mistakes that could affect their performance in the classroom and patient outcome in the clinical setting.

\section{John Deere said:}

I mean, I do use a calculator or pencil or paper when I need to double check or if I am taking a test or something. But, for the most part, like if it's like in a lesson or something, I would just go ahead and then verify my answers with everyone else's answers also. And, so, for everything for drug dosage calculation it's important to make sure that we do the drug calculation several times to make sure that we do it right, especially for narcotics like morphine and stuff like that.

\section{Meghan Brown explained:}

Like I was saying, everything is made available for the nurse in the Pyxis. It even tells you to take 2 tablets, pick-up 3 tablets, but it's important to verify am I picking-up the right $30 \mathrm{mg}$ tablet or not. Insulin does not come prepared, so we prepare it and double verify with the nurse to make sure. I do the math, and I try to understand after I get the number... I ask myself again: does it make sense? I check and recheck.

\section{Zeus stated:}

So, when I see a dose, it's best to recalculate it. Even though, now computer technology has taken away the basic calculation, but, it's always good to kind of look over and to make sure, so that dose is appropriate for that patient, and vice versa. It's always best to do human calculation to verify because technology can make mistakes.

\section{Daphnee said:}

Taking the test is definitely nerve-racking, but what I do is I do all the calculation, and then I check again. You know, I always keep rechecking just to see if, you know, a mistake can go because we always overlook the smallest mistake. So, the smallest mistake can get you a wrong answer. You know, just keep going back to see if any, hum, if anything was wrong with the calculation. We need to take the time to do the calculation ourselves and double check with someone else to see if it's correct, so that the patients would have correct dosing for their illness. 


\section{Maxie noted:}

I realize that it's important because you're looking at the dosage, and you know you have to double check on it. And then, you're looking at the calculation of the tab to give the right dose to the patient.

\section{Barbarita said:}

When I'm passing meds, I always get my piece of paper and do it, and recheck it to do all the steps. I have to do just like I learned in dosage calculation.

\section{Layla stated:}

I always check it with more than one method. I'll do it like this, and I'll do it again, and I'll also convert it backwards, and if it makes sense, then I know it's good.

\section{Theme Four: Repeating}

Repetition means there is recurrence of action that often contributes to familiarity. It is a common technique often utilized by individuals to enhance learning. Repetition is evident in the experiences of all the participants as they expressed its impact on their learning of drug dosage calculation. All the participants reported that practicing what they learned in the classroom facilitates the understanding of the content material.

\section{John Deere explained:}

Practice makes it seems less complicated for him. I was expecting, you know, something super complicated, like you know, millions of formulas to memorize, and then when I actually got to see it, it actually wasn't as bad as I thought further along down the road. But when I first learned it, it was a little rough because, hum, of the way they worded some of the... like the formulas like desired over have time your supply or something. It was a little confusing for me because I am so used to $x$ over $y$ time $z$, something like that. Something very formula linked, and then the more that I did it, the more that I saw that I was actually a lot simpler than it looked, at least for me. It got to the point now where I can do a lot of these calculations in my head without having to really use a calculator or a pencil and paper.

\section{Daphnee indicated:}

So, I mean it was kind of challenging the first few times we gave medications with the dosage calculation, but I guess, the more we practiced, the more we did better with it. I do the remediation provided over and over, huh, and I did well. I know I have to practice the dosage calculation because if I don't pass after three attempts I am out of the program. If the majority of the class had this question wrong, then we would go over it, this question, and then if we had a problem, let's say we missed three out of 10, then we would have to go to the office hours to get a better understanding. I do it at home several times, even in between semesters I continue to do it. It helps me to remember because when I see a dosage problem, you know, I have to get it right.

\section{Jessica stated:}

Certain dosage, you don't want to give too much or too little. You want to make sure of the right thing that you are giving. So, it's important to keep practicing dosage calculation throughout the semester, and stuff like that. We practice the problem, so that with our school, we have each semester, in the beginning, we have a medication competency exam that gives us a chance to study whatever we have to study during our break. This forces you to practice so that we can remember what we've been learning.

\section{Aset reported:}

I know it's very important when we go to the hospitals, we have to... for clinical, we have to, huh, we always practice our dosage calculations whenever we're even practicing to give meds. Even if we aren't the ones administering the medication, we practice. So, I know it's very important. Lives depend on it. We can't get it wrong. The remediation is important to help us see where we went wrong, so we get a better understanding of the problems. They really emphasized how important drug dosage calculation is, and it helps me to realize that I need to practice a lot with the materials they gave us. Practice a lot with my colleagues helps me to be less anxious. We usually go over the packet together. If we don't understand something right away, if one of us takes longer to understand the problems, we go over the problems thoroughly. That's usually works. Practice and more practice of the problems do help a lot.

\section{Blue Orchids discussed:}

Uh, it started off being very difficult because it was something new. But the desired over have, the calculation dealing with tablets, and capsules, and pills, the oral medication, that's wasn't so bad. It was when we drop rates, and drop factors, that was like a whole new language for us. But eventually, we got it. It became easier with time. Well, we know that in order for us to be professional nurses, we have to be able to get the basics down, and so if we don't do so well in our first dosage calculation, we have remediation to go over why we got the answers wrong, or what not. By the second time, we got more of an understanding. Every semester we have to retake it, and every new clinical site that we go to, we have to retake it.

\section{Maxie asserted:}

For me it was a good experience. It helps me increase my math skills toward the dosage calculation. I practice on it with the $C D$, and the more I practice, and practice, I got it. You need to practice, so you don't mess-up on their dosage calculation.

\section{Theme Five: Analyzing}

Analyzing requires detailed inspection of a concept for the understanding of its different aspects [18]. Many of the participants voiced that when they take time to analyze the various components of a drug dosage problem, they usually conclude its computation without any error. They utilize this approach whether they are practicing to enhance learning, or taking a test in the classroom, or administering medications to their assigned patients in the clinical setting.

\section{Daphnee said:}

Hum, to resolve... huh, we... okay, the first thing I do is I look at the problem. I look at what it's asking for. I do my own little question marks. Just little things that will make me remember what to do. Huh, and first I look at what the problem is asking and then go on from there to simplify the dimensional analysis, and then, whatever answer I get, I go back to what the question is asking. 


\section{Meghan Brown explained:}

Well at first, I always read the question, Hum, if I have a diagram, like for example if it gives you a vial, hum, it shows it to you, so I read the question, and then I go from there. If it's, you know, further steps, then I'm like...If I do the math problem, and then it doesn't make sense, I try to make sense of it. So, I'm like: if this the amount of drops per minute? Does that make sense for this drug, or too many tablets, or too little tablets? I try to understand. After I get the number, I ask myself again: does it make sense? I check and recheck.

\section{Zeus explained how she examines drug dosage problem:}

I look at the problem. I see what I need first. The information that it's providing to me, and then I go ahead and solve the problem based on what it's asking of me.

\section{Barbarita said:}

The first thing I do, I just try to understand what the question is asking me first, hum, and then I try to do it in my head, and then after that I actually solve the problem, so that I can compare it to what I can solve in my head versus what I can solve on the paper and following every single step.

\section{Blue Orchids noted:}

Uh, going back to the modules that we learned, and, uh, when I look at the problems... We're taught to make sure to set the situationup because sometimes the word problems can be wordy, and we need to know, as nurses, what's important, and what's not important. Like for example, for reconstitution, it gives you the amount before, and the amount after, and so we learn that what's important is the amount after we add water to dilute it.

\section{Aset explained:}

Huh, usually I make sure that I have all the information needed in front of me before I proceed with the problem. So, I would need... I make sure I have the conversion units, like in peds, whether it's pound to kilogram, hum, I make sure I have the dose that's in the vial, the medication compared to the order given, or how much the patient needs. Yeah, that's what I need. That's what I make sure I have.

\section{Jessica said:}

So, I first look at what the question is about. Then, I look at exactly what we're looking for. For example, are we looking for milliliters, or whatever the question is asking for? Then, you have to, hum, dissect the question to see what's ordered and what's available, and then how you are going to give the medication. You know, to get to how to go about calculating the question.

\section{John Deere explained:}

Whenever I see the questions, I underline what they're asking and go ahead and do the math instead of jumping to do the math because the math is easy. I remember that, hum, for some reason I did not do the right drug calculation, and that was like when I went back to it, like I do when I'm taking a test, and I remember it being $1 \mathrm{mg}$, and the bottle was like $5 \mathrm{mg}$ per milliliter, so I drew-up 1 milliliter thinking like I was fine. And then, I was like wait, that doesn't make any sense. So, I had to go back, and I had to redo it. And then, I realize, yeah, that's why drug calculation is so important.

\section{Theme Six: Assuring Safety}

Safety is the overarching theme that seems to dominate the narrative data of the nursing students. They expressed that patient safety is a priority in any aspect of patient care delivery, especially in drug dosage calculation. They voiced that they learned to perform with the highest level of accuracy to prevent dosage errors that could cause fatal adverse effects to the patients.

\section{John Deere said:}

I can do the calculation right, but the importance of me doing the calculation is with the understanding that I should not give that morphine is the respiration is that low. So, learning drug dosage calculation is the beginning of this learning how to critically think about how to safely treat patients. Especially with the different interventions that we can do. So, learning drug calculation is more than just, okay, the doctor prescribes this, and then, we have to give it. We need to think of patient safety.

\section{Daphnee stated:}

If the dosing is not safe, or overdosing, then, hum, we have a potential to kill the patient. If not kill the patient, then have serious side effects or morbidity. Us as nurses, our priority is to have patient safety. Patient safety is our number one, so, if we have to do the calculation and ask another nurse, or our colleagues, you know, for confirmation, especially as a new nurse.

\section{Jessica said:}

With dosage calculation, you have to make sure that everything is correct and safe. The patient's life is in your hands, you know. That's why us nurses in giving the car, hum, we have to. I know that the doctors are the ones that give order, but we are the first line, the last line that the patient sees. So patient safety is a priority to always keep in mind.

\section{Aset explained:}

Safe dosage calculation, I know, is very important. Lives depend on it. You don't want to get it wrong. So, it means to me being a competent nurse because the bottom line is saving lives.

\section{John Doe said:}

We need to follow the doctor's order, and we want to maintain safety for our patients and have the therapeutic effect the drug is meant for.

\section{Layla indicated:}

We, as nurses, need to give correct medication dosages to our patients. We need to be helping the patients but not do harm to them.

\section{Meghan Brown asserted:}

We need to be doing it correctly for the safety of the patients. Like I said, we can make easy mistakes. You don't want mistakes to harm the patients. 
Citation: Lazare MB (2018) The Lived Experiences of Undergraduate Nursing Students Learning Drug Dosage Calculation. Int J Nurs Clin Pract 5: 297. doi: https://doi.org/10.15344/2394-4978/2018/297

Page 8 of 13

\section{Maxie said:}

Hum, dosage calculation means that you need to learn calculation in a way to not kill the patient. It's about giving safe medications to patients.

\section{Zeus noted:}

I know the process is very critical, and you have to really make sure that you precisely count and do the calculation because any little error could either, you know, could kill somebody.

\section{Barbarita said:}

It's not difficult, and, hum, of course, because of safety, we don't want to make mistakes. With a little error, we can kill a patient. So, that's why I believe it's very good to keep reinforcing it.

\section{Blue Orchids stated:}

We need to make the dosage calculation to know if it's correct before we give it to the patients for their safety. Patient safety is our priority for us nurses to be concerned always. Like, if we gave too little medication for pain, it might not do anything for the patient. Therefore, we have to know what kind of pin they're in, and what was ordered, the safe dosage if it's going to be effective, especially post surgery.

The emergent themes do not define the phenomenon, but they facilitate the researcher to better interpret the meaning of the lifeworlds of the nursing students in their lived world of drug dosage calculation [17]. The researcher was able to depict what the students go through in this specific lifeworld. These themes are not separate entities having their individual occurrence. They are rather interrelated as one can have significant effect on the other.

\section{Discussion}

The purpose of this qualitative phenomenological study was to gain more insight about undergraduate nursing students' lived experiences in learning medication dosage calculation. This study sought to describe and interpret the essence of the lived experiences of undergraduate nursing students mastering drug dosage calculation. Guided by hermeneutic phenomenology, the analysis of each participant's narrative stories led the researcher to depict the meaning of the participants' existentials [17]. This hermeneutic phenomenological inquiry sought to answer the following overarching question: "What is the lived experiences of undergraduate nursing students learning medication dosage calculation?" This study attempted to fill the gap for similar research study revealed in the literature review search. The researcher made a commitment to explore the essence of the phenomenon through the lenses of the nursing students.

The interviews of 11 purposely selected nursing students prompted them to share with the researcher their rich, thick, and in-depth stories of their perceptions of the phenomenon. The meaning of this study was depicted from the themes that emerged from reading, rereading, writing, and reflecting on the stories accounted by the nursing students. Repeated and attentive listening to the voices of the nursing students facilitated the researcher to grasp the essence of what their experiences have been learning drug dosage calculation. The researcher accomplished this essential task while remaining cognizant of personal biases, values, and preconceived notions about the studied phenomenon [18].

The nursing students place great importance on the subject of drug dosage calculation. They embrace its necessity, and they embody it as something of value that must be dealt with in its entirety. They accept the fact that it is an integral part of their nursing program that will be carried over into their daily functions as licensed nurses. This

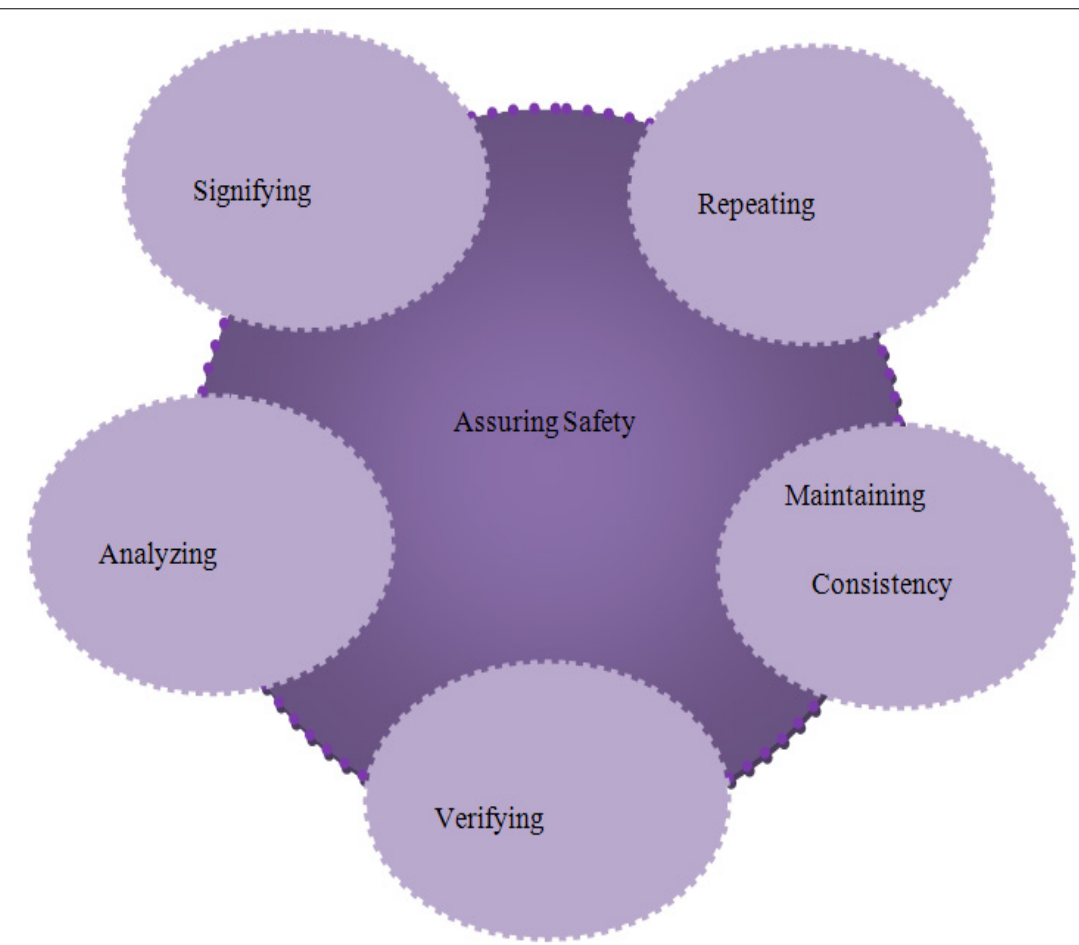

Figure 2: Conceptual Representation of the Lived Experiences of the Participants (Lazare, 2016). 
type of openness to learning drug dosage calculation has made the student nurses more engaging in the learning process. Their mentality is geared toward learning the subject because they understand its significance.

A phenomenological study, conducted to explore undergraduate Thai nursing students' perceptions, regarding learning through the use of problem-based learning (PBL), showed that students with optimistic perception of PBL were more active and productive learners than students with pessimistic perceptions of PBL [23]. A similar tendency on the optimistic aspect was seen in how the nursing students took ownership in learning drug dosage calculation. For these nursing students to become engaged in the learning process, they had to embody the subject in all its intricacies. With this concept, well ingrained in their mind, the students strongly felt the significance of learning drug dosage calculation. The nursing students realized that being cognizant of the significance of learning drug dosage calculation is an open door to its mastery.

The significance that the nursing students attributed to learning drug dosage calculation is manifested in their active learning mentality. The nursing students believed in constant practicing of what they learned in the classroom as being an effective technique to facilitate content retention. They take advantage of any opportunity available at their disposition to practice the subject. They voiced that they practiced alone at their own pace, in groups, and in the clinical area. They also used the remediation review online based on their nursing program. It has been asserted that, for effective learning to take hold, it is crucial to sort out effective means to practice drug calculation problems [24]. The literature review reported that constant repetition is effective on learning regardless of techniques in use [25]. It is always beneficial to incorporate into the learning of drug calculation the techniques that have been proven to improve the acquisition of drug dosage calculation skills [26].

In order to gain understanding of a drug dosage problem, the nursing students examine the problem carefully to carve out the appropriate elements they need to accurately solve the problem. Analysis requires having a clear-thinking skill ability, especially with a topic of such complexity like drug dosage calculation. The nursing students explained that it is necessary to start by reading the problem carefully, and then try to grasp the meaning of the question asked. Once the question is deciphered, it can be connected to the parts in the problem needed for arriving at the correct answer. For easier manipulation of the concepts within a drug dosage problem, it is an important task to identify the different relationships between them [27].

Many of the nursing students indicated that they have used one method or another to solve drug dosage problems. There is more than one method that can be utilized to accurately calculate drug dosages. The commonly known methods are dimensional analysis, formula method, and ratio and proportion. The nursing students in this study reported having embraced either one of these methods, but regardless of the method used, they emphasized on being consistent with the method of choice. Most of the nursing students asserted that the degree of manipulation of a method is the main reason for having chosen it over another.

They all expressed being concerned about administering incorrect medication dosages that can kill a patient. This belief carries them through every day in their lived world of drug dosage calculation.
Their view to do no harm to patients helps them construct a mentality that embraces learning drug dosage calculation as something of significance. The value they attributed to the subject drove their motivation in the direction of student competence. For that, they applied certain strategies in their learning activities to help them achieve the mastery of drug dosage calculation. The right strategies that can help nursing students learn dosage calculation skills are needed for safe medication administration [28]. Patient safety is a priority for all the participants in this study, and they want to prevent medication dosage errors as much as possible. It has been stated that "the practitioner's perspective for error and error causation makes a difference in the robustness of surveillance" [3]. In this study, the participant's perspective is to learn to develop good habits that can lead to safe patient care because potential for good or bad habits is constantly present in one's existence.

This study indicated how the nursing students value drug dosage calculation as a worthwhile subject in their nursing program. This study showed the various mechanisms these students employed on a regular basis to achieve content understanding and its successful application. The most outstanding revelation of this research, or its essence, is that nursing students unanimously emphasized on the direct association of patient safety to accurate drug dosage calculation. The student nurses interviewed were quite enthusiastic about letting the researcher in their lived world of learning drug dosage calculation by participating in face-to-face interviews that were audio taped. One by one they gave rich, vivid, in-depth accounts of their experiences with the phenomenon.

John Deere is a 20-year-old nursing student who acknowledged that he expected learning drug dosage calculation to be complicated, but, surprisingly enough, it was not. He related his ability to understand drug dosage calculation to his prior education in higher levels of math like calculus and statistics. He thought that he would have lots of formulas to memorize, but it was not so difficult after all. However, he mentioned that at first the wording of the formulas was confusing to him because it was different from the algebraic equations that he was used to solving. With constant practice and his focus kept on one formula, John Deere stated that he was able to see that drug dosage calculation is a lot simpler than it appears to be. He further stated: "It got to the point now where I can do a lot of these calculations in my head without having to really use a calculator or a pencil and paper." He did explain that he used calculator to verify that his answers to a problem are correct or not.

John Deere voiced that he understands the action and interaction of drugs have the potential to critically affect all the systems that form the human body, therefore the accuracy of drug dosage calculation is an important aspect of safe medication administration. He stated: "So, learning drug dosage calculation is the beginning of this learning how to critically think about how to treat a patient, especially with the different interventions that we can do, so, that's for me what's important about learning drug dosage calculation." He reported having embraced a systematic way of calculating accurate drug dosage calculation: "Okay, so, first thing I'll do is I'll make sure that I have, like all the units lined-up and stuff, and then I'll go about and do the math, and then the next thing I'll do is to make sure to see if my answer is like correct."

John Deere voiced that he understands the action and interaction of drugs have the potential to critically affect all the systems that form the human body, therefore the accuracy of drug dosage calculation 
is an important aspect of safe medication administration. He stated: "So, learning drug dosage calculation is the beginning of this learning how to critically think about how to treat a patient, especially with the different interventions that we can do, so, that's for me what's important about learning drug dosage calculation." He reported having embraced a systematic way of calculating accurate drug dosage calculation: "Okay, so, first thing I'll do is I'll make sure that I have, like all the units lined-up and stuff, and then I'll go about and do the math, and then the next thing I'll do is to make sure to see if my answer is like correct."

John Deere expressed appreciation for his nursing program for putting drug dosage calculation in every nursing course. He would not want to forget or become mediocre at something that he took time to learn and fully understand. Regardless of being nervous each time he had to take an exam with drug dosage calculation in it, he felt that such an approach would help him maintain and strengthen his knowledge. At the time of the interview, John Deere had not been to the clinical setting yet to administer medication to an actual patient. He had done so in the simulation laboratory. Although he was experiencing anticipatory nervousness, he was looking forward to actually apply what he learned in the classroom to real life situations in the clinical area.

Daphnee is a 22-year-old nursing student who expressed joy and excitement about becoming a nurse. She said that she always wanted to be a nurse as far as she could remember. For her, learning drug dosage calculation has been a great experience. She claimed: "It was basically a straight learning process because our professor made it clear on how to do the dimensional analysis. Nothing too hard or difficult because, you know, I did have, hum, calculus and stats prior to that." She expressed that being competent in drug dosage calculation is a must for nurses because patient safety is a priority. She understood that it is necessary to have a check system in place to identify and eliminate errors that can cause harm to patients. She further stated: "Accurate dosing is important because if it's not therapeutic, the patient is not getting the right treatment, and they would have to keep coming back, or keep getting readmitted because the dosing was not therapeutic." To resolve a drug dosage calculation, Daphnee would analyze the problem to better identify the question being asked, and she would follow specific steps that she developed to help her remember how to use the dimensional analysis to accurately solve the problem. She also stressed the importance of checking and rechecking her answers to ascertain that mistakes are identified and corrected.

Daphnee indicated that taking drug dosage calculation exam made her nervous, especially the first time, but it was more stressful to apply what was learned in the classroom to the clinical setting, especially with pediatric patients. She found the calculation for pediatric patients more complex than for the adult patients. She explained that her nervousness was less intense because she could rely on the guidance of her clinical instructor who was very proficient in the subject. She said that she was also engaged in constant practice sessions either by herself or with other students, as a result, she became more confident and competent in drug dosage calculation. Daphnee indicated that having a knowledgeable professor who can explain the dimensional analysis, which was the only method that they used, was really an advantage.

Jessica is a 21-year-old nursing student who found dosage calculation to be kind of difficult to understand at first. She explained that it was due mostly to the different dynamics involved in the content, which was not the same as what she learned in high school. She stated: "I had to relearn, you know, how to set-up the questions and everything like that, and hum...but overall it was good." She overcame the difficulty due to the knowledgeable teacher who made sure that the content and the dimensional analysis formula were understood. To Jessica, the teacher's ability to make the concept of drug dosage calculation as clear as possible is a very important aspect in learning it.

Jessica indicated that giving correct doses of medications to patients is an important aspect of providing safe nursing care. That is why learning drug dosage calculation correctly is important to her. She understood her responsibility and accountability as a frontline caregiver vis-à-vis safe medication administration. She further stressed the necessity of persistent practice to achieve competency in drug dosage calculation skills. She explained that repetition through continuous practice facilitates her to remember what she learned in the classroom. She is grateful that her school provided ample opportunities to practice even in between semesters when school activities are in recess. When having to solve drug dosage calculation problems either on an exam or in the clinical setting, Jessica does not jump to conclusion. She stated that it is a procedure that requires critical thinking to understand the intent of the question being asked, and it is also important to check and double check for mistakes before deciding the right answer to a problem, or the dose to administer to a patient. Her focus was on being as accurate as possible: "You have to dissect the question, you know, to get to how to go about calculating the question."

Asset is a 20-year-old nursing student who stated that her overall experience learning drug dosage calculation was good. She gave credits to her instructor who taught the dimensional analysis formula in a clear and concise manner that she could understand. She mentioned that she used dimensional analysis in every problem, and she was able to get the right answer each time. Any mistake, most of the time, was because of lack of concentration due to fatigue or not enough sleep. She was thankful for having the opportunity to practice as much as possible, and to be exposed to drug dosage calculation in every nursing course. She stated: "The remediation is important to help us see where we went wrong, so we get a better understanding of the problems."

Aset indicated that she firmly believed that medication administration as an important aspect of nursing caring must be done safely, and accurate dosage calculation must be an integral part of that. She asserted: "It means to me being a competent nurse because the bottom line is saving lives. They really emphasize how important drug dosage calculation is, and it helps me to realize that I need to practice a lot with the materials they give us." When solving a drug dosage problem, Aset would take her time to gather from the problem all the pieces needed to arrive at a correct answer. She said when being evaluated having confidence is one way to minimize her anxiety level. She was more confident when she practiced a lot with her classmates.

Aset found applying drug dosage calculation in the clinical setting was not so nerve-racking as she anticipated it to be because of the unit dose system prepared by pharmacy. However, she said that her clinical instructor wanted the students to do the calculation themselves to prevent drug dosage errors, and to help them maintain competency in drug dosage calculation. She added: "It's also good to double check, pharmacist can make mistakes, human can make mistakes, and the computers are programmed by humans." She recognized an important fact: "I know nurses, in the end, are the ones responsible for their patients, and the outcomes of their patients." 
Blue Orchids is a 23-year-old nursing student who indicated that, at first, learning drug dosage calculation was very difficult for her to grasp. Applying the formula method to calculate oral medications was not as difficult as calculating intravenous (IV) fluid rate per hour, IV drop per minute, and drop factors. She stated that she gained a better understanding after being in the clinical area where she was able to actually observe the impact medications can have on the patient outcome. She explained: "It's very important that we make sure that it's within the safe range, especially with pediatric medications because they go by kilogram, by weight."

Blue Orchids indicated that students in her nursing program were not allowed in the clinical setting unless they scored $100 \%$ on their drug dosage calculation examination. The students were not seen as competent if they did not have a perfect score. She did her best to understand the materials and the formula method to accurately resolve dosage problems because after a third failure she would be expelled from the program. She expressed satisfaction with the many remediation sessions that were made available to facilitate learning. She also valued having to be evaluated in drug dosage calculation every semester and in any new clinical setting, where its application to real life situations makes it completes.

John Doe is a 22-year-old nursing student who had an overall good experience learning drug dosage calculation. He found it to be simple mathematics that one can do if time is devoted to its understanding and mastery. He understood that dosage calculation is important for nursing students to be competent at because in case of an emergency, or computer failure, nurses need to rely on their knowledge to provide safe patient care. Being competent in drug dosage calculation increases his level of confidence because he knows that he is less likely to administer a dose that may not be therapeutic to the patient. He stated: "We obviously know there is always risks for overdosing, always risks for interactions, and you need to give the right amount to the right patient that's in the order."

John Doe explained that he uses the formula method along with common sense and critical thinking to resolve drug dosage calculation problems. He approaches such task with confidence because of his ability to comprehend mathematics.

Barbarita is a 24-year-old nursing student who learned mathematics initially in Columbia, her native country. Although she is grateful for her background, but learning dosage calculation was quite challenging because of the difference in the way she learned mathematics in her country. She has managed to learn drug dosage calculation by including what she already has in her repertoire to what she is learning in the classroom. She understood that it is important to be competent in drug dosage calculation skills to prevent medication dosage errors that can lead to patient morbidity or mortality. Therefore, learning drug dosage calculation means a lot to Barbarita: "It means being sure that we're doing it the correct way." Barbarita uses the ratio and proportion method formula to calculate dosages. She said it is easier for her as a method, and it is not far from what she learned in her country of origin. She was more likely to feel nervous when facing evaluation in drug dosage calculation, but she was always able to compose herself to concentration because she is comfortable with mathematics. She was very nervous taking her very first exam because of uncertainty of the outcome, but, in the end, she was satisfied with her performance. She does not want to make mistakes in the clinical setting when giving medications to patients. Therefore, she follows the same classroom principle of checking and rechecking her answers to avoid a dosage error. She explained: "It's better to be safe than sorry, and there is a human life, and you don't play with that."

Zeus is a 38-year-old nursing student who had a good experience learning drug dosage calculation. She initially learned mathematics in Créole, her first language, but she is fluent in English. She said that learning dosage calculation helps her with critical thinking skills that she needs to prevent medication errors. Zeus made sure to focus and pay attention to every detail in the classroom content needed to be confident in dosage calculations. Dimensional analysis is her preferred method to solve dosage problems because, in her opinion, it has more precision. She further indicated: "Some people use ratio and proportion, but I personally like dimensional analysis because it gives me a more of a clearer path so that I don't miss a step."

Zeus reported that she was very anxious the first time she was being evaluated on drug dosage calculation because she did not want to make mistakes. The approach that has been successful for Zeus is to carefully analyze the dosage problem presented before making any attempt to solve it. She further emphasized on the importance of paying attention to every detail in the content to know exactly what must be included in the calculation to obtain the correct answer. In the clinical area, Zeus does not rely solely on what the computers says the dose should be. She recalculated the dosage ordered to make sure of its accuracy.

Layla is a 21-year-old nursing student who claimed to understand the logic behind learning drug dosage calculation. She viewed knowing how to accurately calculate drug dosage as one of the important skills to master to minimize or prevent medication errors. It was a good experience for her because she has a good aptitude for learning mathematics and any subject associated with it. She was comfortable using the formula method and the other methods, such as dimensional analysis and ratio and proportion, to resolve dosage problems. In addition, she regularly engaged herself in group study sessions to strengthen content knowledge learned in lecture. She stated that learning drug dosage calculation increases her level of confidence, which helps to alleviate her anxiety level during an examination and in the clinical setting. Layla wanted to make sure drug errors were identified and remedied before they could cause harmful impact on patient care.

Meghan Brown is a 22-year-old nursing student who, at first, had some level of difficulty with learning drug dosage calculation. In the beginning, the content materials, and the intricacy of the formulas were overwhelming to her. However, with regular practice sessions, and the use of only the formula method, the concepts became easier to understand, and her ability to safely calculate drug dosages was improved. She explained that it is easy to make mistakes in drug dosages that can affect someone's life, therefore understanding medication administration must be taken very seriously. She appreciated learning dosage calculation because it helps with her confidence and critical thinking skills. For example, when being evaluated, she would take time to read and examine the questions thoroughly before proceeding to the computation part. She checked and rechecked to make sure the answer was correct. The subject is of great importance to her; thus, she incorporated measures to assure a successful outcome.

Meghan Brown stated being evaluated in drug dosage calculation always evoked nervousness because a perfect score was expected, and she could only take the exam three times. If she failed on the third attempt, she would be expelled from the program. This type of 
condition, although she understood the rationale for it, still increased her anxiety level because she did not want to fail. Meghan observed that it was easier in the clinical setting because of technology. However she realized dosage calculation competence is crucial because not all drugs prepared in single dose, and the nurse needs to make sure the dose is correct before giving it to the patient.

Maxie is a 22-year-old nursing student who had a positive view on learning drug dosage calculation. She stated that it is an important component of patient care. Understanding how to calculate dosages was not easy for Maxie. She enhanced her learning by pairing the classroom content with continuous practice done at her own pace. She associated being competent in dosage calculation skills to safe medication administration. The mastery of drug dosage calculation has helped increase her confidence, which kept her anxiety level under control when being evaluated on content knowledge. Maxie emphasized on checking and rechecking for mistakes to make sure of the correct answer to a calculation problem. She was looking forward to applying her drug dosage calculation skills to real patients in the clinical area. She anticipated being nervous in the clinical area, but she could rely on her clinical instructor to guide her through the process.

Human behavior is not influenced by one causative factor of either internal or external in aspects [29]. Human motivation and behavior are influenced by factors that are personal, behavioral, and environmental in nature [30]. These factors are interrelated, and they interact and influence each other as determinant of behaviors [30]. Individuals are agent of their own actions based on how their cognition experiences their external world [30]. The themes of signifying, repeating, analyzing, verifying, maintaining consistency, and assuring safety reflect the students' self-beliefs, expectations, goals, intentions, and thought process as personal factors and behavioral factors. The overarching theme of assuring safety, the force that drives the students to success, the very essence of their lived experiences, represents environmental factors as well as personal, and behavioral factors.

\section{Implications for Nursing Education}

Drug dosage calculation is a complex task that nursing students must learn with proficiency because medication administration is an important facet of the nursing profession. For many years, the health care facilities have been using the unit dose system of dispensing medications to reduce medication error. However, certain medications, such as emergency medications, insulin, and pediatric medications, to name a few, are not supplied in unit dose packages. Even with a smooth working technology and an adequate support from pharmacy, the nurse remains the practitioner who directly administers medication to patients [2]. Therefore, nurses are responsible and accountable for safe medication administration to patients [2].

The findings of this study provided empirical knowledge that gave insights on how the nursing students perceived becoming competent in drug dosage calculation. They expressed having a positive mentality about learning it because they do not want to harm patients. Patient safety was revealed as their principal motivator for learning drug dosage calculation. Patient safety is the essence of their perspectives on learning drug dosage calculation. Their interest in the subject is important for learning to take place. These nursing students were motivated to learning drug dosage calculation successfully. As a result they were engaged in repeating, analyzing, maintaining consistency, verifying, and assuring safety. These students demonstrated a sense of ownership of their responsibility to the provision of safe medication administration.

These insights from this study can contribute to the development of specfic strategies for teaching students content understanding and retention, and how to apply their knowledge in the clinical settings. However, what needs to be done first is to develop curricula that support consistency in the methods utilized for content teaching. Such curricula should also be designed to engrain into students the importance of learning drug dosage calculation. The findings indicate that nursing students favor, for the most part, having a specific teaching methodology for learning drug dosage calculation. Therefore, it would be beneficial for acadmia to come to a consensus as to which teaching methodology student nurses in their institutions need to achieve competency in the subject. Nurse educators need to be cognizant of the complexity of drug dosage calculation, which requires more than lectures and evaluations of learning for students to achieve competency.

\section{Limitations}

Although this qualitative study generated in-depth information rooted in real life experiences of the participants that yielded to meaningful explanation of a complex phenomenon, it was not without limitations. Qualitative inquiries rely strongly on human experiences to generate its characteristics [31]. Limitations are to be considered in the fact that the data generation, collection, and analysis are very subjective. The findings generated from the study may not be suitable for transferability due to their individualized characteristics. Qualitative research may be difficult to understand and utilize in a clinical setting because of the individualistic nature of it [32]. For example, sampling method of qualitative research is usually snowballing, purposive sampling rather than random selection. The characteristics of the qualitative method requirethat chosen participants be experienced with the phenomenon in study. Accounts from both the participants and the researcher must be handled with considerations [33]. The participants may not be completely honest in their answers to questions asked during the interview, or they may withhold information from the researcher due to issues such as lack of trust or embarrassment. The researcher's preconceived ideas or lack of experience could have an impact on the results of the study.

\section{Recommendations}

Recommendations for future study were generated based on the findings of the study. The participants verbalized having embraced various learning techniques that have landed them effective performances in drug dosage calculation. The emergent themes included signifying, repeating, analysing, maintaining consistency, verifying, and assuring safety. The participants considered learning drug dosage calculation as something very important that they need to perform correctly to avoid hurting patients. The significance these students attached tolearning drug dosage calculation is what drove their determination to learning it succesfully. The researcher recommendsa mixed methods study to determine the correlation between viewing drug dosage calculation as significant and self motivation to learning dosage calculation proficiently, and their perspectives on patient safety. Another correlational study to take into consideration is the association between constant practice and understanding of drug dosage calculation. Since the participants'demographic data revealed that they had advanced mathematics at the collegiate level, the researcher recommend a prospective study to compare the 
performance on drug dosage calculation of students with advanced college level math with the performance of students who only had high school or intermediate college level math. Lastly, the lived experiences of student nurses who are mandated to learning dosage calculation with one drug dosage calculation method.

\section{Conclusion}

This qualitative inquiry was the first of its kind to explore the lived experiences of undergraduate baccalaureate nursing students learning drug dosage calculation. Based on the findings, this phenomenological study can encourage further communication on teaching strategies and best practices to promote student success, and more research studies to address more specific issues related to the phenomenon. Eleven purposively selected participants volunteered to share with the researcher in-depth accounts of their experiences about their lived world of learning drug dosage calculation The researcher followed the guidance provided by van Manen's six research activities for rigorous analysis of the data, which led to the emergent themes of signifying, repeating, analyzing, maintaining consistency, verifying, and the overarching theme of assuring safety. The researcher was immersed in the narratives of the participants in order to interpret the essence of their lived experiences. These participants gave rich, in-depth accounts of how they embodied drug dosage calculation in order to attain competence that they need to administer correct dosage of medications to their patients, to whom they want to do no harm. Patient safety is revealed as the essence of the lived experiences of the participants learning drug dosage calculation.

\section{Competing Interests}

The author declares no competing interests.

\section{References}

1. Institute of Medicine (2006) Preventing medication errors.

2. Lin FY, Wu WW, Lin HR, Lee TY (2014) The learning experiences of student nurses in pediatric medication management: A qualitative study. Nurse Educ Today 34: 744-748.

3. Ford EW, Savage GT (2008) Patient Safety: State-of-the-art in healthcare management and future directions. Advances in Healthcare Management 7: 1-14.

4. McMullan M, Jones R, Lea S (2010) Patient safety: Numerical skills and drug calculation abilities of nursing students and registered nurses. J Adv Nurs 66: 891-899.

5. Richardson B, Bromirski B, Hayden A (2012) Implementing a safe and reliable process for medication administration. Clin Nurse Spec 26: 169-176.

6. Wright $\mathrm{K}$ (2005) An exploration into the most effective way to teach drug calculation skills to nursing students. Nurse Educ Today 25: 430-436.

7. Choo J, Hutchinson A, Bucknall T (2010) Nurses' role in medication safety. J Nurs Manag 18: 853-861.

8. Kohtz C, Gowda C (2010) Teaching drug calculation in nursing education: A comparison study. Nurse Educ 35: 83-86.

9. Greenfield S, Whelan B, Cohn E (2006) Use of dimensional analysis to reduce medication errors. Journal of Nursing Education 45: 91-94.

10. Stolic S (2014) Educational strategies aimed at improving student nurse's medication calculation skills: A review of the research literature. Nurse Educ Pract 14: 491-503.

11. Harris MA, Pittiglio L, Newton SE, Moore G (2014) Using simulation to improve the medication administration skills of undergraduate nursing students. Nurs Educ Perspect 35: 26-29.

12. Jackson NV, De Carlo JJ (2011) Problem solved dosage calculation in a nursing program. Nurse Educ 2: 80-83.
13. Wright K (2012) Student nurses' perceptions of how they learn drug calculation skills. Nurse Education Today 32: 721-726.

14. Fleming S, Brady AM, Malone AM (2013) An evaluation of the drug calculation skills of registered nurses. Nurse Educ Pract 14: 55-61.

15. Morris DG (2010) Calculate with confidence. St Louis, MO: Mosby.

16. Van Manen, M (2014) Phenomenology of practice. Walnut Creek, CA: Left Coast Press.

17. Van Manen, M (1990) Researching lived experience: Human science for an action sensitive pedagogy. Albany NY: State University of New York Press.

18. Creswell JW (2013) Qualitative inquiry and research design: Choosing among five approaches (3rd ed). Thousand Oaks, CA: Sage.

19. Francis JJ, Johnston M, Robertson C, Glidewell L, Entwistle V, et al. (2010) What is an adequate sample size? Operationalising data saturation for theory-based interview studies. Psychol Health 25: 1229-1245.

20. Rubin HJ, Rubin IS (2012) Qualitative interviewing: The art of hearing data. Los Angeles, CA: Sage.

21. Lincoln YS, Guba EG (2013) The constructivist credo. Walnut Creek, CA: Left Coast Press.

22. Guba EG, Lincoln YS (1989) Fourth generation evaluation. Newbury Park, CA: Sage Publications, Inc

23. Arpanantikul M, Luecha $Y$ (2010) Problem-based learning: Undergraduate Thai nursing students' perceptions. Pacific Rim International Journal of Nursing Research 3: 262-276.

24. Wright $K$ (2008) Can effective teaching and learning strategies help student nurses to retain drug calculation skills? Nurse Education Today 28: 856-864.

25. McMullan $M$, Jones $R$, Lea $S$ (2011) The effect of an interactive e-drug calculations package on nursing students' drug calculation ability and selfefficacy. Int J Med Inform 80: 371-454

26. Kelly L E, Colby N (2003) Teaching medication calculation for conceptual understanding. J Nurs Educ 42: 468-471.

27. Wright $K$ (2009) Developing methods for solving drug dosage calculations. Br J Nurs 18: 685-689.

28. Wright $\mathrm{K}$ (2007) Student nurses need more than maths to improve their drug calculating skills. Nurse Educ Today 27: 278-285.

29. Bandura A (1989) Social cognitive theory. Annals of child development 6 : $1-60$.

30. Bandura A (1986) Social foundations of thought and action: A social cognitive theory. Englewood Cliffs NJ: Prentice Hall.

31. Polit DF, Beck CT (2012) Generating and assessing evidence for nursing practice. Hong Kong: Lippincott Williams \& Wilkins.

32. Holloway I, Wheeler S (2002) Qualitative research in nursing. Malden MA: Blackwell Science.

33. Munhall PL (2012) Nursing research: A qualitative perspective. Sudbury MA: Jones \& Bartlett. 